\title{
Influence of $\mathrm{Xe}^{+}$Irradiation on Topography and Wettability of Graphite Surface
}

\author{
I. TAShlykov ${ }^{a, *}$, A. TuRAvets $^{a}$ And P. Zhukowski ${ }^{b}$ \\ ${ }^{a}$ Belarussian State Pedagogical University, 18 Sovetskaja, 220050 Minsk, Belarus \\ ${ }^{b}$ Lublin University of Technology, Nadbystrzycka 38d, 20-618 Lublin, Poland
}

\begin{abstract}
The investigation of influence of $\mathrm{Xe}^{+}$ions irradiation of graphite on its surface topography and wettability was conducted. With the increase of the irradiation dose, the roughness average increases rapidly at first (when the sample was irradiated at the dose of $1 \times 10^{14} \mathrm{~cm}^{-2}$ ) and then decreases slowly. The atomic force microscopy three-dimensional pictures showed that after irradiation of graphite of $\mathrm{Xe}^{+}$ions with a dose of $3 \times 10^{15} \mathrm{~cm}^{-2}$ hemispherical grains (from 0.2 to $0.8 \mu \mathrm{m}$ in diameter) appear on its surface. Surface water contact angle measurement showed that irradiation of graphite by $\mathrm{Xe}^{+}$ions leads to a hydrophobic surface of graphite. We have observed that irradiation of graphite by $\mathrm{Xe}^{+}$ions can be used for obtaining graphite surface with desirable topography and water wettability.
\end{abstract}

PACS: 81.05.uf, 61.80.-x, 68.37.Ps

\section{Introduction}

Graphite is a candidate material for many technological applications, such as barrier or antifriction coating, foundry facings, etc. Thus the surface properties, such as morphology, mechanical properties and wettability, are important for the performance of the final system, therefore they have attracted considerable interest of many investigators recently [1-5]. Studies devoted to the investigation of the irradiation of graphite show that its properties are greatly affected by ion irradiation. However, the effect of irradiation on the morphology and the wettability of graphite as well as the mechanisms of the change of these properties remain unclear up to date.

This work deals with the influence of $\mathrm{Xe}^{+}$ions irradiation of graphite on its surface topography and wettability.

\section{Experimental}

Typically graphite samples had a size of $10 \times$ $8 \mathrm{~mm}^{2}$ and thickness of $3 \mathrm{~mm}$. They were irradiated by $20 \mathrm{keV} \mathrm{Xe}{ }^{+}$ions. The beam current density was kept of $1.2 \mu \mathrm{A} / \mathrm{cm}^{2}$. The dose of ions was $1 \times 10^{14}, 3 \times 10^{14}$, $1 \times 10^{15}, 3 \times 10^{15}$ ions $/ \mathrm{cm}^{2}$, the corresponding irradiation time was $13,40,133,400 \mathrm{~s}$, respectively. During the irradiation, vacuum pressure was $4 \times 10^{-4} \mathrm{~Pa}$. The holder with the target was covered with the shield cooled by liquid nitrogen, thus avoiding redeposition of sputtered elements.

* corresponding author; e-mail: tashl@bspu.unibel.by
Atomic force microscopy (AFM) study of graphite samples was performed using the NT-206 microscope ("Microtestmashines") in the contact mode with the silicon cantilever tips CSC21 ("MicroMash"). Roughness values in this paper refer to those of the average surface roughness, $R_{\mathrm{a}}$, calculated from the AFM surface topographic data. Contact angle measurement was based on the sessile-drop method described in [6]. The wetting agent was doubly distilled water.

\section{Results and discussion}

\subsection{Surface morphology}

The AFM was utilized to examine the topography and the roughness of graphite samples. The images are shown in Fig. 1A-D. These pictures indicate clearly how the shape of the surface changes with the increase of the irradiation dose. The topography parameters are listed in Table.

TABLE

The topography parameters and significances of the measured contact angles of the investigated samples.

\begin{tabular}{c|c|c|c|c|c}
\hline \hline $\begin{array}{c}\text { Irradiation dose } \\
\left.\text { [ions } / \mathrm{cm}^{2}\right]\end{array}$ & initial & $1 \times 10^{14}$ & $3 \times 10^{14}$ & $1 \times 10^{15}$ & $3 \times 10^{15}$ \\
\hline nominal area $\left[\mu \mathrm{m}^{2}\right]$ & 401.2 & 401.2 & 401.2 & 401.2 & 401.2 \\
full area $\left[\mu \mathrm{m}^{2}\right]$ & 434.9 & 426.5 & 432.0 & 430.3 & 419.5 \\
$R_{\text {a }}[\mathrm{nm}]$ & 226.2 & 309.7 & 294.7 & 257.2 & 233.5 \\
CA [degrees] & 70.6 & 116.2 & 123.9 & 119.9 & 93.2
\end{tabular}

Initially, the surface topography of the graphite had irregularly distributed valleys (typically a few $\mu \mathrm{m}$ wide 


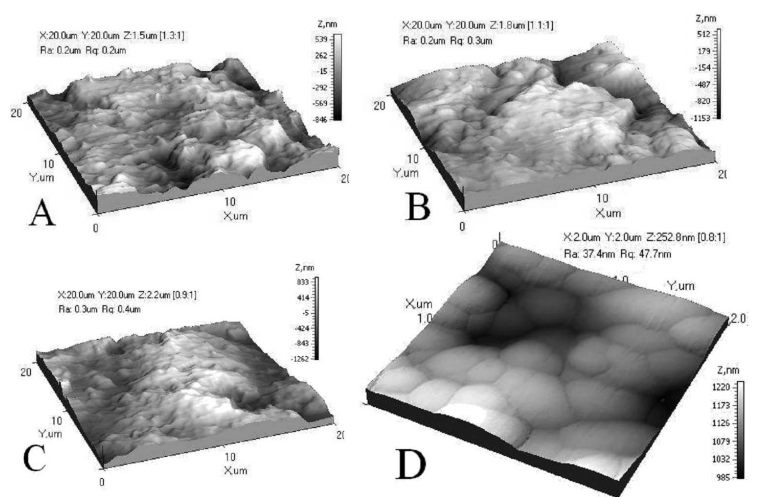

Fig. 1. AFM images of the initial graphite (A) and $\mathrm{Xe}^{+}$irradiated graphite at $1 \times 10^{14}$ ions $/ \mathrm{cm}^{2}(\mathrm{~B})$, $3 \times 10^{14}$ ions $/ \mathrm{cm}^{2}(\mathrm{C}), 3 \times 10^{15}$ ions $/ \mathrm{cm}^{2}(\mathrm{D})$. Scan area was $20 \times 20 \mu \mathrm{m}^{2}(\mathrm{~A}, \mathrm{~B}, \mathrm{C})$ or $2 \times 2 \mu \mathrm{m}^{2}$ (D).

and 200-300 $\mathrm{nm}$ deep) and hills (large, about $10 \mu \mathrm{m}$ in diameter, and small, $\approx 1 \mu \mathrm{m}$ in diameter), Fig. $1 \mathrm{~A}$.

The AFM representations of $\mathrm{Xe}^{+}$irradiated graphite at $1 \times 10^{14}$ ions $/ \mathrm{cm}^{2}$ (Fig. $1 \mathrm{~B}$ ) show that mainly small flakes disappeared and the pores between the flakes became deeper (as a result, the full area of the surface of graphite decreases and its $R_{\mathrm{a}}$ increases, Table). In other words, the surface of graphite became simpler, and represents a set of large inhomogeneities, separated by deep pores.

When the irradiation doses were $3 \times 10^{14}$ ions $/ \mathrm{cm}^{2}$ and higher, the process of sputtering of the surface was more uniform. As a result, pores between the flakes became wider and hillocks assumed a rounded shape, Fig. 1C. The AFM three-dimensional pictures show that after irradiation of graphite of $\mathrm{Xe}^{+}$ions with a dose of $3 \times 10^{15} \mathrm{~cm}^{-2}$ hemispherical grains (from 0.2 to $0.8 \mu \mathrm{m}$ in diameter) appear on its surface (Fig. 1D), it could be attributed to the formation of xenon bubbles on the graphite surface.

Suvorov et al. [7] reported the presence of certain threshold values of the irradiation dose for each type of ions, the excess of which leads to the decrease of $R_{\mathrm{a}}$ of the surface of graphite, or at least, its constancy. Our measurements are in a good agreement with that $R_{\mathrm{a}}$ of the initial graphite was found to be $226.2 \mathrm{~nm}$. Dependence of $R_{\mathrm{a}}$ on the irradiation dose is indicated in Fig. $2 \mathrm{~A}$. It is shown that $R_{\mathrm{a}}$ is increased by $37 \%$ at the first stage (from 0 to $1 \times 10^{14} \mathrm{ions} / \mathrm{cm}^{2}$ ). When the irradiation dose is higher than $1 \times 10^{14}$ ions $/ \mathrm{cm}^{2}$ (from $1 \times 10^{14}$ to $3 \times 10^{15}$ ions $/ \mathrm{cm}^{2}$ ), the average roughness is decreased (Fig. 2A). These results indicate the possibility of managing the roughness of the graphite surface by changing the dose during irradiation.

The possible mechanisms of the formation of the surface irradiated graphite are formation of the amorphous phase, accumulation of Xe atoms in the surface layers of graphite, as well as sputtering the surface and the precipitation of sputtered carbon. The shield cooled by liquid

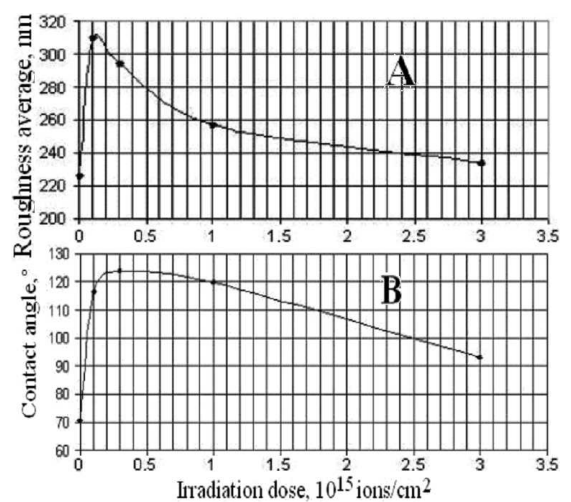

Fig. 2. Evolution of $R_{\mathrm{a}}(\mathrm{A})$ and the contact angle (B) vs. the irradiation dose.

nitrogen efficiently prevents redeposition of sputtered elements. The dependence of $R_{\mathrm{a}}$ on a dose of ion irradiation, as we assume, is connected with primitive accumulation of Xe atoms in the surface layers of graphite and breaking of basic planes of graphite, the possibility of which was reported by the authors [8], who studied the influence of $\mathrm{N}^{+}$irradiation $\left(30 \mathrm{keV}, 10^{16}-10^{18} \mathrm{~cm}^{-2}\right)$ on topography of a surface and structure nearsurface layer of graphite.

\subsection{Wettability test}

Figure 3 shows the position of a water drop on the surface of the initial graphite and $\mathrm{Xe}^{+}$irradiated graphite. Mean values of water contact angle (CA) at five different positions were recorded and averaged in Table. In Fig. 2B the variation of $\mathrm{CA}$ of samples with the irradiation dose is given.
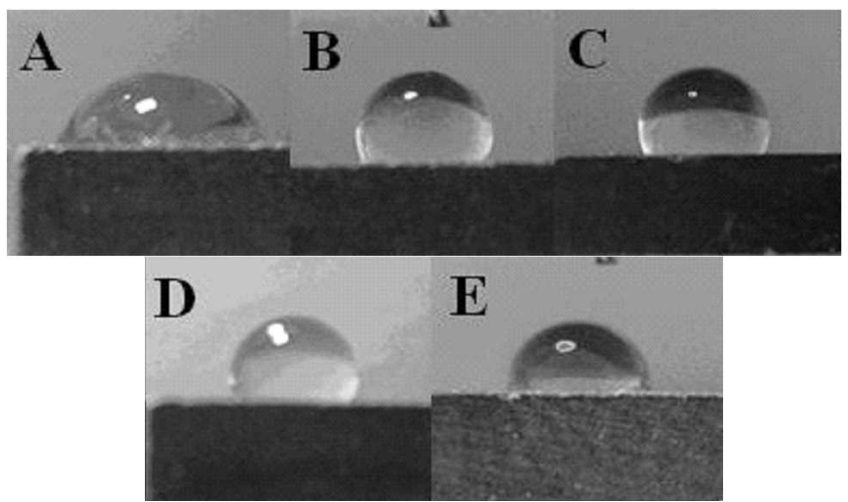

Fig. 3. Water drops on the surface of the initial graphite (A) and $\mathrm{Xe}^{+}$irradiated graphite at $1 \times$ $10^{14}$ ions $/ \mathrm{cm}^{2}(\mathrm{~B}), 3 \times 10^{14}$ ions $/ \mathrm{cm}^{2}(\mathrm{C}), 1 \times 10^{15}$ ions $/ \mathrm{cm}^{2}(\mathrm{D}), 3 \times 10^{15}$ ions $/ \mathrm{cm}^{2}(\mathrm{E})$.

The wettability test results show fundamental difference between the contact angle of initial graphite $\left(70.6^{\circ}\right)$ and the contact angle of experimentally modified surfaces $\left(93.2^{\circ}-123.9^{\circ}\right)$. Irradiation of graphite of $\mathrm{Xe}^{+}$ions leads to a hydrophobic surface of graphite. 
The dependence of the value $\mathrm{CA}$ on a dose of ion irradiation (Table, Fig. 2B), as traced by the change in the form of water drops on the surface of the samples (Fig. 3A-E), is similar to that of the average roughness from a dose.

These results indicate the possibility of managing the water wettability of the graphite surface by changing the dose during irradiation.

\section{Conclusions}

Investigation of influence of $\mathrm{Xe}^{+}$ions irradiation of graphite on its surface topography and wettability was conducted.

We have shown in this paper the presence of threshold value of the irradiation dose for $\mathrm{Xe}^{+}\left(1 \times 10^{14} \mathrm{ions} / \mathrm{cm}^{2}\right)$, the excess of which leads to the decrease of $R_{\mathrm{a}}$ of graphite. With the increase of the irradiation dose, the roughness average increases rapidly at first (when the sample is irradiated at the dose of $1 \times 10^{14} \mathrm{~cm}^{-2}$ ) and then decreases. Probably this dependence could be explained by primitive accumulation of Xe atoms in the surface layers of graphite and by breaking of basic planes of graphite, which facilitates the sputtering of the surface.

The AFM three-dimensional pictures showed that after irradiation of graphite of $\mathrm{Xe}^{+}$ions with a dose of $3 \times$ $10^{15} \mathrm{~cm}^{-2}$ hemispherical grains (from 0.2 to $0.8 \mu \mathrm{m}$ in diameter) appear on its surface, it could be attributed to the formation of xenon bubbles on the graphite surface.

Contact angle measurement showed that irradiation of graphite of $\mathrm{Xe}^{+}$ions leads to a hydrophobic surface of graphite. Graphs of the dependence of $\mathrm{CA}$ and $R_{\mathrm{a}}$ vs. the irradiation dose are similar.

We have observed that irradiation of graphite of $\mathrm{Xe}^{+}$ions can be used for receiving graphite surface with desirable topography and water wettability.

\section{References}

[1] I.A. Faizrakhmanov, V.V. Bazarov, A.L. Stepanov, I.B. Khaibullin, Semiconductors 6, 748 (2003).

[2] A.M. Borisov, V.V. Zheleznov, V.S. Kulikauskas, E.S. Mashkova, W. Eckstein, J. Surf. Investig. X-ray Synchrotron Neutron Techn. 5, 58 (2001).

[3] A.Yu. Didyk, S.V. Latyshev, V.K. Semina, A.E. Stepanov, A.L. Suvorov, A.S. Fedotov, Yu.N. Cheblukov, Techn. Phys. Lett. 17, 1 (2000).

[4] N.N. Andrianova, A.M. Borisov, V.S. Kulikauskas, E.S. Mashkova, A.S. Nemov, Yu.S. Virgiliev, S.Ja. Betsofen, Problems At. Sci. Technol. 4, 37 (2008).

[5] I.V. Amirkhanov, A.Yu. Didyk, A. Hofman, I.V. Puzynin, V.K. Semina, Yu.N. Cheblukov, Phys. Element. Particles At. Nuclei 6, 1592 (2006).

[6] I.S. Tashlykov, S.M. Baraishuk, Izv. VUZov Powder Metallurgy Funct. Coat. 1, 30 (2008).

[7] A.L. Suvorov, Yu.N. Cheblukov, N.E. Lazarev, A.F. Bobkov, M.O. Popov, V.P. Babaev, Techn. Phys. 3, 56 (2000).

[8] E.A. Ligacheva, M.G. Ivanov, N.V. Gavrilov, D.R. Emlih, S.Ja. Betsofen, A.E. Ligachev, V.V. Sohoreva, Izv. VUZov Powder Metallurgy Funct. Coat. 2, 42 (2008). 